\title{
Prevalence of Dental Erosion among the Young Regular Swimmers in Kaunas, Lithuania
}

\author{
Andrius Zebrauskas ${ }^{1}$, Ruta Birskute ${ }^{1}$, Vita Maciulskiene ${ }^{1}$ \\ ${ }^{1}$ Department of Dental and Oral Pathology, Faculty of Odontology, Lithuanian University of Health Sciences.
}

\author{
Corresponding Author: \\ Ruta Birskute \\ S. Zukausko 3-21, LT-49405, Kaunas \\ LT- 54350, Domeikava \\ Lithuania \\ Phone: +37063471014 \\ E-mail: ruta.birskute@gmail.com
}

\section{ABSTRACT}

Objectives: To determine prevalence of dental erosion among competitive swimmers in Kaunas, the second largest city in Lithuania.

Material and Methods: The study was designed as a cross-sectional survey, with a questionnaire and clinical examination protocols. The participants were 12 - 25 year-old swimmers regularly practicing in the swimming pools of Kaunas. Of the total of 132 participants there were 76 (12 - 17 year-old) and 56 (18 - 25 year-old) individuals; in Groups 1 and 2, respectively. Participants were examined for dental erosion, using a portable dental unit equipped with fibre-optic light, compressed air and suction, and standard dental instruments for oral inspection. Lussi index was applied for recording dental erosion. The completed questionnaires focused on the common erosion risk factors were returned by all participants.

Results: Dental erosion was found in $25 \%$ of the $12-17$ year-olds, and in $50 \%$ of 18 - 25 years-olds. Mean value of the surfaces with erosion was 6.31 (SD 4.37). All eroded surfaces were evaluated as grade 1. Swimming training duration and the participants' age correlated positively (Kendall correlation, $\mathrm{r}=0.65, \mathrm{P}<0.001$ ), meaning that older swimmers had practiced for longer period. No significant correlation between occurrence of dental erosion and the analyzed risk factors (gastroesophageal reflux disease, frequent vomiting, dry mouth, regular intake of acidic medicines, carbonated drinks) was found in both study groups.

Conclusions: Prevalence of dental erosion of very low degree was high among the regular swimmers in Kaunas, and was significantly related to swimmers' age.

Keywords: tooth erosion; swimming; swimming pools.

\author{
Accepted for publication: 13 June 2014 \\ To cite this article: \\ Zebrauskas A, Birskute R, Maciulskiene V. Prevalence of Dental Erosion among the Young Regular Swimmers in Kaunas, \\ Lithuania. \\ J Oral Maxillofac Res 2014;5(2):e6 \\ URL: http://www.ejomr.org/JOMR/archives/2014/2/e6/v5n2e6ht.pdf \\ doi: $10.5037 /$ jomr.2014.5206
}




\section{INTRODUCTION}

Dental erosion is defined as loss of tooth structure by acid dissolution without the involvement of bacteria. It is an increasing problem in today's society, because of the changing lifestyle and nutrition. Numerous reports in literature indicate that the prevalence of dental erosion seems to be rising dramatically in young populations, with varying data from 11 to $100 \%$ in different countries [1-3]. The results of the national survey in Iceland showed that the frequency of dental erosion among 15 year-olds doubled when compared to the 12 year-old children [4]. Furthermore, males seem to develop more erosion than females [1].

Pathogenesis mechanism of dental erosion is based on dissociation of hydroxyapatite and on impaired mineralization of the dental hard tissue due to long and frequent effect of acids [5]. For the erosion to progress, the solution $\mathrm{pH}$ level has to be below 5.5 for enamel and below 6.0 for dentine [ 6,7$]$. A number of external or internal causes can be responsible for the $\mathrm{pH}$ drop at tooth surfaces; however development of the erosive process depends on the interplay of different biological, behavioural and chemical factors involved in it. Most often reported risk factors of dental erosion are digestive and eating disorders (GERD, regurgitation, bulimia, anorexia etc.) as well as frequent consumption of acidic drinks and beverages [8]. Occupation and sports can add to development of erosive wear in some patients as well [9]. Amongst those, there might be individuals exposed to acids at the working place (pharmaceutical enterprise, wine tasting etc.) or, individuals engaged in heavy physical activity and using acidic sports drinks to compensate dehydration. A particular group of athletes is people who spend much time in pool water such as swimmers, water polo players and divers. Chlorine compounds are used for disinfection of water in swimming pools. The main disinfection techniques used are gas chlorination or sodium hypochlorite. Chlorine compounds dissolve in water and change the $\mathrm{pH}$ level. The water $\mathrm{pH}$ level can decrease from 7.4 to 4 over night because of inadequate buffering of $\mathrm{HCl}$ when gas chlorination system is used [10]. Chlorine can also be added to pool water as sodium hypochlorite $(\mathrm{NaOCl})$, which has an alkaline $\mathrm{pH}$ and, thus, limited erosion potential [11]. A case study by Dawes et al. [12], reported about a complete loss of enamel by acid erosion, particularly from the anterior teeth in a person who swam daily for two weeks in an improperly chlorinated swimming pool. In several epidemiological studies, the prevalence of dental erosion among swimmers varied between $26 \%$ to $90 \%$ of swim team members $[\underline{11}, \underline{13}, \underline{14}]$.

Swimming is a popular sport activity in Lithuania. Thus, the purpose of the present study was to estimate the prevalence of dental erosion among the different age groups of regular swimmers; and to analyze correlation of dental erosion with their sport regimen and other potential risk factors of erosive tooth wear.

\section{MATERIAL AND METHODS}

The study population consisted of 12 - 25 year-old participants practicing swimming regularly in the swimming pools of Kaunas, Lithuania. In total, there are 5 swimming pools in Kaunas (Kaunas swimming school with 3 swimming pools, Lithuanian Sports University - 1 swimming pool and Kaunas Center sport school - 1 swimming pool). All swimmers of the selected age, who practice in Kaunas swimming pools, were invited to take part in the study. However, 50 swimmers of Kaunas Center sport school, and 12 swimmers from Kaunas swimming school and Lithuanian Sports University were not interested to participate. Participation was voluntary. The participants were informed about the purposes of the study and the informed consent was obtained. The parents' approvals for the participants under age of 18 were obtained as well. The Bioethics Committee at Lithuanian University of Health Sciences provided ethical approval for the study (BEC-OF-321, BECOF-322). The data were collected during May and June of 2013.

Of the total of 194 of $12-25$ year-old regular swimmers in Kaunas, 132 agreed to participate in the study. The participants were divided in two groups according to their age: $12-17$ year-olds (Group 1) and 18 - 25 year-olds (Group 2). There were 76 swimmers (50 males, 26 females) in Group 1 , and 56 swimmers ( 34 males, 22 females) in Group 2 , respectively. All participants went through a clinical dental examination at the premises of the swimming pools, using a portable dental unit equipped with fibre-optic operation light, compressed air and a suction device (Dentronic, Aarhus, Denmark), and standard dental instruments for oral inspection (dental mirror and dental explorer). The occlusal, facial and labial surfaces of all teeth were examined for dental erosion, using Lussi index [15] (Table 1). The clinical examinations were performed by one examiner. The intra-examiner reliability was tested by repeating the examinations of 20 participants $(10 \%$ of the study 
Table 1. Clinical criteria for assessment of dental erosion by Lussi [토]

\begin{tabular}{c|l|l}
\hline & \multicolumn{1}{|c|}{ Facial surfaces } & \multicolumn{1}{c}{ Occlusal/oral surfaces } \\
\hline 0 & $\begin{array}{l}\text { No erosion. Surface with a smooth, silky glazed appearance, } \\
\text { absence of developmental ridges possible }\end{array}$ & $\begin{array}{l}\text { No erosion. Surface with a smooth, silky-glazed appearance. } \\
\text { Absence of developmental ridges possible }\end{array}$ \\
\hline 1 & $\begin{array}{l}\text { Loss of surface enamel. Intact enamel found cervical to the lesion } \\
\text { concavity in enamel, the width of which clearly exceeding its } \\
\text { depth, thus, distinguishing it from toothbrush abrasion, undulating } \\
\text { borders of the lesions are possible dentine is not involved }\end{array}$ & $\begin{array}{l}\text { Slight erosion, rounded cusps, edges of restorations rising } \\
\text { above the level of adjacent tooth surface, grooves on occlusal } \\
\text { aspects. Loss of surface enamel. Dentine is not involved }\end{array}$ \\
\hline 2 & Involvement of dentine for less than one-half of the tooth surface & $\begin{array}{l}\text { Severe erosion, more pronounced signs than grade 1. Dentine } \\
\text { is involved }\end{array}$ \\
\hline 3 & Involvement of dentine for more than one-half of the tooth surface & \\
\hline
\end{tabular}

population), within the 2 days interval between the examinations. Cohen's Kappa was calculated at 0.91 representing good agreement for reproducibility of erosion.

All participants responded to an anonymous questionnaire related to the most common risk factors of dental erosion. The questionnaire was adopted from previous studies $[16,17]$. The questions in the questionnaire covered background information about the respondent's age and gender as well as about training time and hours spent per week in a swimming pool (one hour was considered as one training); feeling of dental hypersensitivity; bruxism and other related disorders and symptoms (GERD, increased acidity of the stomach, frequent vomiting, dry mouth); regular intake of acidic medicines such as vitamin $\mathrm{C}$ and acetylsalicylic acid; carbonated soft drinks and sport drinks consumption.

The quality of water in the pools was estimated based on the data provided by the pool workers (water monitoring is performed twice a day). The parameters of water quality varied between the set limits of water $\mathrm{pH} 7$ - 7.5, and chlorine concentration $0.5-2 \mathrm{mg} / \mathrm{l}$.

\section{Statistical analysis}

The data were analyzed by means of SPSS software (SPSS 20.0 for Windows). The sample size calculation was based on Paniotto formula that resulted in the minimum of 130 individuals to participate in the survey. The data were described using mean (M) values, standard deviation (SD), 95\% confidence intervals (CI). The distribution and qualitative variables were compared by Chi-square $\left(\chi^{2}\right)$ test. Depending on the sample size, Fisher's exact test (for small samples) and asymptomatic $\chi^{2}$ were applied. Correlation of quantitative variables was assessed by Kendall and Spearman correlation analyses. Prognostic values of the selected risk factors expressed as odds ratios (OR) and confidence intervals (95\% CI), were estimated by means of univariate binary logistic regression analysis.

To verify the statistical hypotheses, the significance level of 0.05 was chosen.

\section{RESULTS}

The total number of study participants was 132 . Group 1 comprised 76 individuals of age $12-17$ years, and Group 2 - 56 individuals of age $18-25$ years, respectively. Gender distribution was similar in both groups (Table 2). Swimming training duration and the participants' age had significant positive correlation (Kendall correlation analysis, $\mathrm{r}=0.65$, $\mathrm{P}<0.001$ ), meaning that older participants had attended swimming for a longer period. However, the swimmers in Group 2 spent significantly less hours per week in the swimming pool as compared to the swimmers in Group 1 (Table 2).

A total of 21, 120 dental surfaces of the study participants were examined. Dental erosion was observed in 296 surfaces (1.4\% of the total number of surfaces examined). Forty seven participants (35.6\%) had at least one eroded tooth surface. The mean value of the surfaces affected by dental erosion in the total study group was 6.31 (4.37). The lesions were distributed mainly on the labial and oral surfaces of the anterior teeth and premolars, no signs of erosion were observed on the molar teeth. All lesions of dental erosion were valuated as grade 1 according to Lussi index [15].

The prevalence of dental erosion was 25\% (19 individuals) in Group 1, significantly lower than the estimated 50\% (28 individuals) in Group 2.

The prevalence of dental erosion according to swimming training duration and hours spent per week in a swimming pool is shown in Table 3.

The distribution of dental erosion according to gender, did not differ significantly among the females and males, although a tendency of higher prevalence of eroded dental surfaces among the male participants was observed: in $33 \%(n=16)$ of the girls 
Table 2. Comparison of the study groups according to gender, swimming training time, and hours spent per week in a swimming pool

\begin{tabular}{|c|c|c|c|c|}
\hline & Total $(n=132)$ & Group $1(n=76)$ & Group $2(n=56)$ & \multirow{2}{*}{ P-value/ $\chi^{2}$; d.f.; P-value } \\
\hline & $\mathbf{N}(\%)$ & N (\%) & $\mathrm{N}(\%)$ & \\
\hline \multicolumn{5}{|l|}{ Gender } \\
\hline Male & $84(63.6)$ & $50(65.8)$ & $34(60.7)$ & \multirow{2}{*}{0.549} \\
\hline Female & $48(36.4)$ & $26(34.2)$ & $22(39.3)$ & \\
\hline \multicolumn{5}{|c|}{ Training duration (years) } \\
\hline$<5$ & $26(19.7)$ & $24(31.6)^{b}$ & $2(3.6)^{b}$ & $\chi^{2}=69.6 ;$ d.f. $=2$ \\
\hline $5-10$ & $58(43.9)$ & $47(61.8)^{\mathrm{c}}$ & $11(19.6)^{\mathrm{c}}$ & $\mathrm{P}<0.001^{\mathrm{a}}$ \\
\hline$>10$ & $48(36.4)$ & $5(6.6)^{d}$ & $43(76.8)^{d}$ & ${ }_{b, c, d} \mathrm{P}<0.001^{\mathrm{a}}$ \\
\hline \multicolumn{5}{|c|}{ Hours spent per week in a swimming pool (h) } \\
\hline$<4$ & $28(21.3)$ & $11(14.5)^{\mathrm{b}}$ & $17(30.4)^{b}$ & $\chi^{2}=6.353 ;$ d.f. $=2 ;$ \\
\hline $4-6$ & $25(18.9)$ & $13(17.1)$ & $12(21.4)$ & $\mathrm{P}=0.042^{\mathrm{a}}$ \\
\hline$>6$ & $79(59.8)$ & $52(68.4)^{c}$ & $27(48.2)^{\mathrm{c}}$ & ${ }^{b, c} \mathrm{P}<0.03^{\mathrm{a}}$ \\
\hline
\end{tabular}

a Statistically significant, Chi-square test.

$\chi^{2}=$ Chi-square test; d.f. $=$ degree of freedom.

Table 3. The prevalence of dental erosion according to swimming training duration and hours spent per week in a swimming pool

\begin{tabular}{|c|c|c|c|c|}
\hline \multirow{3}{*}{ Groups } & \multicolumn{3}{|c|}{ Training duration (years) } & \multirow{3}{*}{$\chi^{2}$; d.f.; P-value } \\
\hline & $<5$ & $5-10$ & $>10$ & \\
\hline & $\mathbf{N}(\%)$ & $\mathbf{N}(\%)$ & $\mathbf{N}(\%)$ & \\
\hline Group $1(n=76)$ & $5(20.8)$ & $13(27.7)$ & $1(20)$ & $\chi^{2}=0.466 ;$ d.f. $=2 ; \mathrm{P}=0.792$ \\
\hline Group $2(n=56)$ & $1(50)$ & $5(45.5)$ & $22(51.2)$ & $\chi^{2}=0.114 ;$ d.f. $=2 ; \mathrm{P}=0.945$ \\
\hline \multirow{2}{*}{ Groups } & Hour & veek in the & pool (h) & \multirow{2}{*}{$\chi^{2}$; d.f.; P-value } \\
\hline & $<4$ & $4-6$ & $>6$ & \\
\hline Group $1(n=76)$ & $2(18.2)$ & $4(30.8)$ & $13(25)$ & $\chi^{2}=0.503 ;$ d.f. $=2 ; \mathrm{P}=0.777$ \\
\hline Group $2(n=56)$ & $7(41.2)$ & $6(50)$ & $15(55.6)$ & $\chi^{2}=0.863 ;$ d.f. $=2 ; \mathrm{P}=0.65$ \\
\hline
\end{tabular}

$\chi^{2}=$ Chi-square test; d.f. $=$ degree of freedom.

and $37 \%(\mathrm{n}=31)$ of the boys $(\mathrm{P}=0.68)$. Respectively, in Group 1: $23 \%(\mathrm{n}=6)$ of the girls and $26 \%(\mathrm{n}=13)$ of the boys $(\mathrm{P}=0.78)$; in Group 2: 46\% $(\mathrm{n}=10)$ of the girls and $53 \%(\mathrm{n}=18)$ of the boys $(\mathrm{P}=0.58)$.

Figure 1 shows that some of the well known risk factors of dental erosion were highly prevalent among the study participants: about half of all swimmers indicated drinking carbonated soft drinks daily, and almost one third of the swimmers indicated drinking sport drinks on the daily basis.

As shown in Table 4, the presence of dental erosion was significantly associated with swimmers' age and training duration. The $18-25$ year-old participants and those who practiced swimming for more than 10 years had 3 times greater risk to develop dental erosion than the younger swimmers $(12-17$ yearolds) and those who practiced swimming less than 10 years.

Among all participants, $17 \%$ of the swimmers complained of dental hypersensitivity. There was no significant difference in the prevalence of dental hypersensitivity neither between two study groups nor between females and males. A very weak correlation between the reported dental hypersensitivity and presence of dental erosion $(\mathrm{r}=1.124, \mathrm{P}=0.124)$ was estimated. Only $23 \%$ of those who presented with dental erosion, reported about hypersensitivity as well. Of all participants, $13 \%$ complained about dental hypersensitivity with no dental erosion recorded.

\section{DISCUSSION}

The purpose of the present study was to explore possible correlations of the swimming regimen and the selected risk factors of dental erosion among the regular swimmers in Kaunas, Lithuania. In all swimming pools of Kaunas the sodium hypochlorite disinfection system is used. The results showed that $25 \%$ of the $12-17$ year-old participants had dental erosion, whereas the prevalence of dental erosion amongst the $18-25$ year-olds was $50 \%$. The prevalence of dental erosion did not correlate with the duration of swimming and time spent per week in pool, in both age groups of the participants. However, it did correlate significantly with the participant's age. 


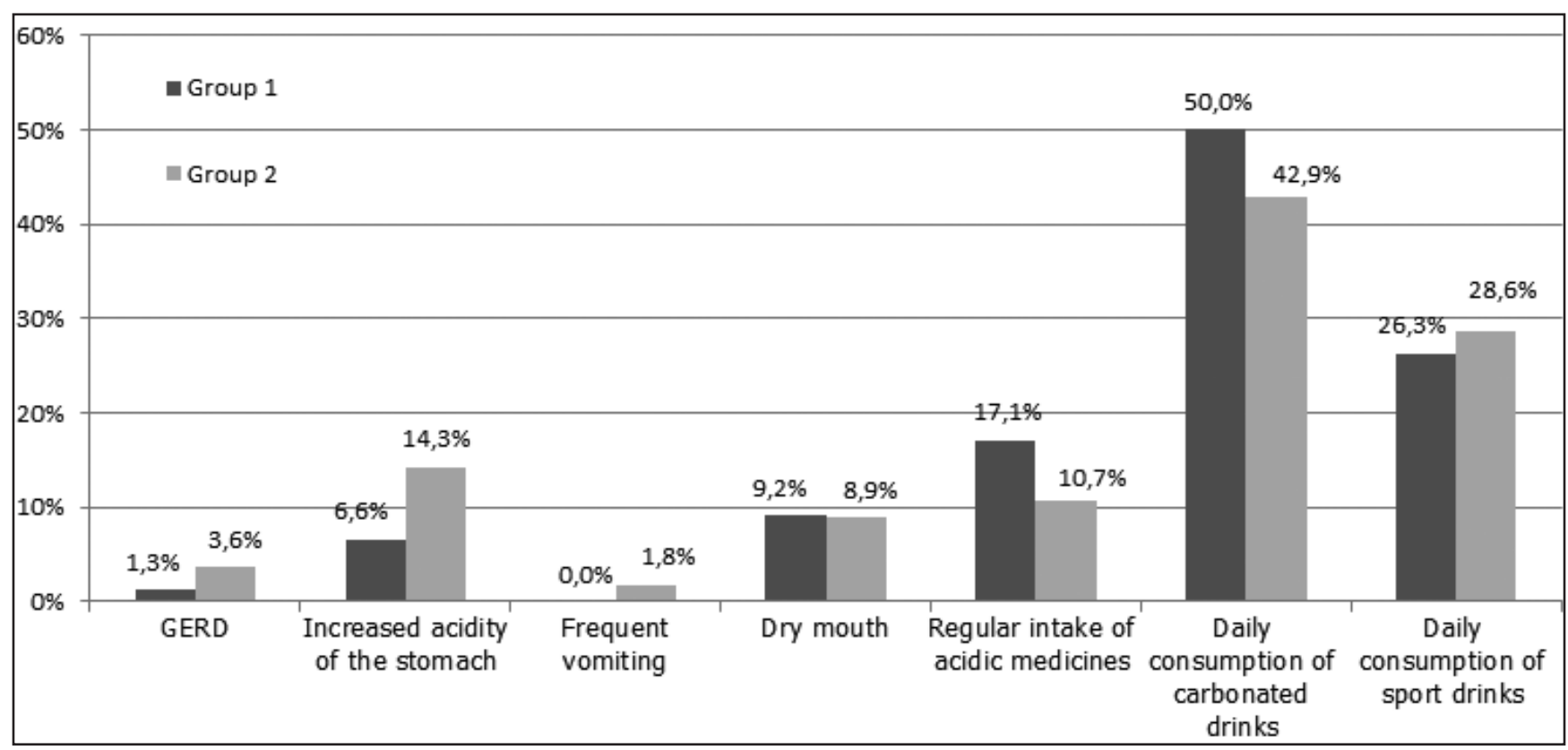

Figure 1. The reported prevalence of the potential risk factors of the erosive dental wear among the study participants.

Table 4. Univariate binary logistic regression analysis of the prevalence of dental erosion, with respect to the selected risk factors

\begin{tabular}{l|c}
\hline \multicolumn{1}{c|}{ Risk factors } & OR [95 \% CI] \\
\hline Group 2 ( 18 - 25 year-olds) & $3.0[1.435-6.272], \mathrm{P}=0.004^{\mathrm{a}}$ \\
\hline Training duration 5- 10 years & $1.5[0.515-4.367], \mathrm{P}=0.457$ \\
Training duration > 10 years & $3.067[1.048-8.974], \mathrm{P}=0.041^{\mathrm{a}}$ \\
\hline Hours spend per week in a swimming pool 4 - 6 hours. & $1.407[0.456-4.342], \mathrm{P}=0.552$ \\
Hours spend per week in a swimming pool > 6 hours. & $1.159[0.463-2.901], \mathrm{P}=0.753$ \\
\hline Complaints about GERD/ increased acidity of the stomach/frequent vomiting/dry mouth & $0.823[0.339-1.999], \mathrm{P}=0.667$ \\
\hline Regular intake of acidic medicines (vitamin C, acetylsalicylic acid) & $1.065[0.388-2.919], \mathrm{P}=0.903$ \\
\hline Daily consumption of sweet, carbonated drinks & $0.99[0.485-2.022], \mathrm{P}=0.978$ \\
\hline Daily consumption of sport drinks & $1.031[0.464-2.29], \mathrm{P}=0.941$ \\
\hline
\end{tabular}

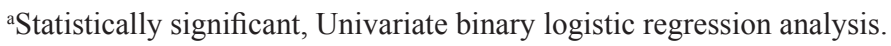

All lesions of dental erosion were valuated as grade 1 according to Lussi index [15], the same results were found in a similar study by Buczkowska-Radlińska et al. [11].

There are numerous reports in the literature indicating that people who spend a lot of time in a swimming pool such as swimmers, water polo players, divers have an elevated risk to develop dental erosion [1014, 18-21].

However, development of dental erosion was mainly showed in studies performed in gas chlorinated pools $[11, \underline{12}, \underline{19}, \underline{20}]$. On the contrary, in the countries where sodium hypochlorite disinfection method is used for disinfection of pool water only $0.14 \%$ pools had $\mathrm{pH}$ level lower than 5.5 , which is a critical value with respect to decalcification of dental tissues $[6,21]$.

However, as suggested by Buczkowska-Radlińska et al. [11] low $\mathrm{pH}$ of pool water is not exclusively responsible for the dental hydroxyapatite dissolution process, but the concentration of ions with respect to the saturation of dental hydroxyapatite, especially calcium and phosphate, may also be involved. Long-term exposure to the pool water undersaturated with respect to hydroxyapatite could be responsible for erosive damage of dental tissues, particularly in the labial surfaces of teeth. Labial erosions were found more frequently in males, who practiced long swimming sessions and an aggressive style of swimming, involving increased agitation (e.g., when a swimmer is swishing water in the mouth) [11]. Another report [22] suggested that even in properly maintained gas-chlorinated swimming pools basic salivary parameters (salivary flow rate, concentration of minerals in saliva) of the swimmers might be altered thus contributing to enamel dissolution.

Moreover, competitive swimmers often use sport drinks during training time. High intake of sports drinks during exercise, coupled with xerostomia from dehydration, may lead to the possibility of erosive damage to teeth as well [23]. 
Swimmers also experience physiological decrease of saliva flow because of body's dehydration during training. The effect of sport drinks, possible low swimming pool water $\mathrm{pH}$ and undersaturation of hydroxyapatite minerals accumulates and possibly increases the risk of dental erosion.

The small sample size did not allow us to find any significant correlations with other potential risk factors of dental erosion, such as reflux, increased acidity of the stomach, dry mouth, regular intake of acidic medicines (vitamin $\mathrm{C}$, acetylsalicylic acid), or consumption of carbonated beverages and sport drinks. However, the reported prevalence of daily consumption of the soft drinks was high amongst the study participants. Considering the fact that there was no correlation with the swimmer's time (number of hours) spent in swimming pools, it seems that a cumulative effect of various factors, related to the lifestyle of young people, might have occurred. Further research involving larger study samples would be beneficial in order to estimate the severity of dental erosion among different population groups in Lithuania.

\section{CONCLUSIONS}

The prevalence of dental erosion of very low degree among the regular swimmers of Kaunas city was high and significantly related with age. Double estimates were found in 18 - 25 year-old swimmers as compared to their $12-17$ year-old colleagues.

\section{ACKNOWLEDGMENTS AND DISCLOSURE STATEMENTS}

The authors would like to thank Irena Nedzelskiene (Lithuanian University of Health Sciences, Faculty of Odontology, Department of Dental and Oral Pathology) for her help in statistical analysis and to the swimming schools and all the participants who participated in this survey.

The authors report no conflicts of interest related to this study.

\section{REFERENCES}

1. Jaeggi T, Lussi A. Prevalence, incidence and distribution of erosion. Monogr Oral Sci. 2006;20:44-65. Review. [Medline: 16687884] [doi: 10.1159/000093350]

2. Bartlett DW, Lussi A, West NX, Bouchard P, Sanz M, Bourgeois D. Prevalence of tooth wear on buccal and lingual surfaces and possible risk factors in young European adults. J Dent. 2013 Nov; 41(11): 1007-1013. Epub 2013 Sep 1. [Medline: 24004965] [doi: 10.1016/j.jdent.2013.08.018]

3. Isaksson $\mathrm{H}$, Birkhed $\mathrm{D}$, Wendt LK, Alm A, Nilsson M, Koch G. Prevalence of dental erosion and association with lifestyle factors in Swedish 20-year olds. Acta Odontol Scand. 2013; Nov 28 [Medline: 24286494] [doi: 10.3109/00016357.2013.859727]

4. Arnadottir IB, Holbrook WP, Eggertsson H, Gudmundsdottir H, Jonsson SH, Gudlaugsson JO, Saemundsson SR, Eliasson ST, Agustsdottir H. Prevalence of dental erosion in children: a national survey. Community Dent Oral Epidemiol. 2010 Dec;38(6):521-526. [Medline: 20690934] [doi: 10.1111/j.1600-0528.2010.00559.x]

5. Featherstone JD, Lussi A. Understanding the Chemistry of Dental Erosion. In: Lussi A, editor. Dental Erosion. From Diagnosis to Therapy. Karger, 2006;20:66-76.

6. Meurman JH, ten Cate JM. Pathogenesis and modifying factors of dental erosion. Eur J Oral Sci. 1996 Apr;104(2 (Pt 2)):199-206. [Medline: 8804887] [doi: 10.1111/j.1600-0722.1996.tb00068.x]

7. Vanuspong W, Eisenburger M, Addy M. Cervical tooth wear and sensitivity: erosion, softening and rehardening of dentine; effects of pH, time andultrasonication. J Clin Periodontol. 2002 Apr;29(4):351-7. [Medline: 11966933] [doi: 10.1034/j.1600-051X.2002.290411.x]

8. Zero DT, Lussi A. Erosion--chemical and biological factors of importance to the dental practitioner. Int Dent J. 2005;55(4 Suppl 1):285-90. [Medline: 16167607]

9. Lussi A, Jaeggi T. Erosion--diagnosis and risk factors Clin Oral Investig. 2008 Mar;12 Suppl 1:S5-13. Epub 2008 Jan 29. [Medline: 18228059 ] [doi: $10.1007 / \mathrm{s} 00784-007-0179-\mathrm{z}]$

10. Centers for Disease Control (CDC). Erosion of dental enamel among competitive swimmers--Virginia. MMWR Morb Mortal Wkly Rep. 1983 Jul 22;32(28):361-2. [Medline: 6408379]

11. Buczkowska-Radlińska J, Łagocka R, Kaczmarek W, Górski M, Nowicka A. Prevalence of dental erosion in adolescent competitive swimmers exposed to gas-chlorinated swimming pool water. Clin Oral Investig. 2013 Mar;17(2):579-83. Epub 2012 Apr 3. [Medline: 22476450] [doi: 10.1007/s00784-012-0720-6]

12. Dawes C, Boroditsky CL. Rapid and severe tooth erosion from swimming in an improperly chlorinated pool: case report. J Can Dent Assoc. 2008 May;74(4):359-61. [Medline: 18538074] 
13. Centerwall BS, Armstrong CW, Funkhouser LS, Elzay RP. Erosion of dental enamel among competitive swimmers at a gas-chlorinated swimming pool. Am J Epidemiol.1986 Apr;123(4):641-7. [Medline: 3953542]

14. Baghele ON, Majumdar IA, Thorat MS, Nawar R, Baghele MO, Makkad S. Prevalence of dental erosion among young competitive swimmers: a pilot study. Compend Contin Educ Dent. 2013 Feb;34(2):e20-4. [Medline: 23627405]

15. Lussi A. Dental erosion clinical diagnosis and case history taking. Eur J Oral Sci. 1996 Apr;104(2 (Pt 2)):191-8. [Medline: $\underline{8004886}$ ] [doi: 10.1111/j.1600-0722.1996.tb00067.x]

16. Mathew T, Casamassimo PS, Hayes JR. Relationship between sports drinks and dental erosion in 304 university athletes in Columbus, Ohio, USA. Caries Res. 2002 Jul-Aug;36(4):281-7. [Medline: 12218278] [doi: 10.1159/000063927]

17. Árnadóttir IB, Sæmundsson SR, Holbrook WP. Dental erosion in Icelandic teenagers in relation to dietary and lifestyle factors. Acta Odontol Scand. 2003 Feb;61(1):25-8. [Medline: 12635777]

18. Savad EN. Enamel erosion: multiple cases with a common cause (?). J N J Dent Assoc. 1982 Winter;53(1):32, 35-7, 60. [Medline: 6951962]

19. Gabai Y, Fattal B, Rahamin E, Gedalia I. Effect of $\mathrm{pH}$ levels in swimming pools on enamel of human teeth. Am J Dent. 1988 Dec;1(6):241-3. [Medline: 3270559]

20. Geurtsen W. Rapid general dental erosion by gas-chlorinated swimming pool water. Review of the literature and case report. Am J Dent. 2000 Dec;13(6):291-3. [Medline: 11764119]

21. Lokin PA, Huysmans MC. Is Dutch swimming pool water erosive? Ned Tijdschr Tandheelkd. 2004 Jan;111(1):14-6. [Medline: 14768239]

22. Bretz WA, Carrilho MR. Salivary Parameters of Competitive Swimmers at Gas Chlorinated Swimming-Pools. J Sports Sci Med. 2013 Mar 1;12:207-208. [Medline: 23536742] [PMC free article: 3607459]

23. Noble WH, Donovan TE, Geissberger M. Sports drinks and dental erosion. J Calif Dent Assoc. 2011 Apr;39(4):233-8. [Medline: 21675676]

\section{To cite this article:}

Zebrauskas A, Birskute R, Maciulskiene V. Prevalence of Dental Erosion among the Young Regular Swimmers in Kaunas, Lithuania.

J Oral Maxillofac Res 2014;5(2):e6

URL: http://www.ejomr.org/JOMR/archives/2014/2/e6/v5n2e6ht.pdf

doi: $10.5037 /$ jomr.2014.5206

Copyright (C) Zebrauskas A, Birskute R, Maciulskiene V. Published in the JOURNAL OF ORAL \& MAXILLOFACIAL RESEARCH (http://www.ejomr.org), 1 July 2014.

This is an open-access article, first published in the JOURNAL OF ORAL \& MAXILLOFACIAL RESEARCH, distributed under the terms of the Creative Commons Attribution-Noncommercial-No Derivative Works 3.0 Unported License, which permits unrestricted non-commercial use, distribution, and reproduction in any medium, provided the original work and is properly cited. The copyright, license information and link to the original publication on (http://www.ejomr.org) must be included. 